\title{
Pulse Wave Velocity is an Independent Predictor of Office Hypertension
}

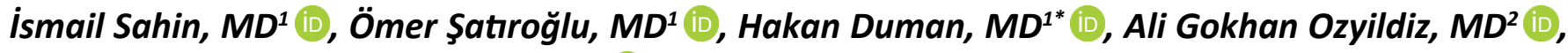 \\ and Murtaza Emre Durakoğlugil, $M D^{1}$ iD \\ ${ }^{1}$ Department of Cardiology, Medical Faculty, Recep Tayyip Erdoğan University, Rize, Turkey \\ ${ }^{2}$ Department of Cardiology, Recep Tayyip Erdoğan University Training and Research Hospital, Rize, Turkey

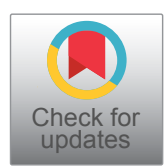

*Corresponding author: Hakan Duman, MD, Department of Cardiology, Medical Faculty, Recep Tayyip Erdoğan University, 53100 Rize, Turkey, Tel: (+90)-4642123000; (+90)-538-276-33-57, Fax: (+90)-464-212-30-15

\begin{abstract}
Aim: Carotid-femoral pulse wave velocity (cf-PWV) is the gold standard measure of arterial stiffness and a stronger predictor of poor outcomes for cardiovascular events. Pulse wave velocity is closely related to blood pressure, but its effect on office hypertension (OHT) is unclear. The study aims to investigate the relationship between $\mathrm{OHT}$ and cf-PWV.

Materials and methods: This was a prospective, singlecenter, clinical trial. A total of 102 subjects were included in the study: 48 patients with OHT and 54 subjects with normal blood pressure. Clinical risk factors and biochemical parameters were noted. Subjects underwent an assessment of cf-PWV by the validated tonometric system (SphygmoCor). The healthy group and the OHT group were compared.

Results: Demographic and clinical parameters did not differ between groups. However, cf-PWV values were higher in the OHT group compared to healthy subjects. $(9.0 \pm 1.7 \mathrm{~m} / \mathrm{s}$ vs. $7.9 \pm 1.8 \mathrm{~m} / \mathrm{s}, p=0.002)$. The cf-PWV was correlated with systolic blood pressure, $(r=0.310, p=0.002)$, and found as an independent predictor of OHT. ROC analysis identified that PWV levels had moderate sensitivity and specificity for predicting OHT.

Conclusion: The patients with OHT have higher cf-PWV values compared to healthy subjects. Pulse wave velocity plays a role in the pathophysiology of OHT, and is an independent predictor of it.
\end{abstract}

\section{Keywords}

Office hypertension, Pulse wave velocity, Arterial stiffness

\section{Introduction}

Studies have been demonstrated a better cardiovascular prognosis for isolated office hypertension (OHT) (white-coat hypertension) patients than those with sustained hypertension [1-4]. However, its prognostic significance is controversial when compared to healthy subjects $[5,6]$. Isolated $\mathrm{OHT}$ is associated with structural cardiac abnormalities, and increased left ventricular mass, a well-known cardiovascular risk marker, is one of these abnormalities [7-10].

Carotid-femoral pulse wave velocity (cf-PWV) is a measure of the intrinsic stiffness of the aortic wall and is a predictor of cardiovascular events. The prognostic importance of cf-PWV is that it is considered as an integral measure of the adverse hemodynamic effects of aortic stiffness [11]. Once aortic stiffness occurs systolic pressure and pulse pressure increase and myocardial perfusion pressure decreases [12-14].

High PWV values are involved in the pathophysiology of OHT. Hypertension leads to increased aortic stiffness and PWV, resulting in target organ damage. Office hypertension causes an increase in aortic stiffness and, therefore, an increase in PWV. So, PWV may be an independent predictor of OHT. In this study, we aimed to investigate whether PWV can be used to predict OHT.

\section{Material and Methods}

\section{Study population}

The prospective study included 175 consecutive subjects, and after exclusion criteria were applied, 102 of them were analyzed. Blood pressure measurement at rest was performed with a sphygmomanometer, and at least two measurements above $140 / 90 \mathrm{mmHg}$ 
were defined as hypertension [15]. Subjects were divided into two groups; the first group consisted of 48 hypertensive patients, and the second group consisted of 54 age and gender matched normotensive subjects. Subjects with sinus rhythm and normal left ventricular systolic function were included in the study. Patients with moderate/severe valvular disease, ascending aorta dilatation, coronary artery disease, peripheral artery disease, and carotid artery disease were excluded from the study.

\section{Study protocol}

Pulse wave velocity was calculated using SphygmoCor (AtCor Medical Instruments, New South Wales, Australia) branded tonometry device. First, suprasternal notch-femoral distance and suprasternal notch-carotid distance measurements were performed with a standard tape measure, and data were entered into the device. In the device, the "intersecting tangents" were used as the NDH algorithm, and it was set to compare the 10-second recordings. The pressure waveforms of the carotid and femoral arteries of the patients were measured noninvasively by placing the pressure-sensitive transducer in the relevant places on the neck and groin. The device automatically calculated $\mathrm{NDH}$ values by dividing the suprasternal notch-femoral distance and the suprasternal notch-carotid distance difference by the pulse wave transit time. Patients were excluded if the standard deviation was greater than $10 \%$, or the difference between the pulses at the two measuring sites was more than five beats $/ \mathrm{min}$.

\section{Statistical analysis}

The SPSS statistical software (SPSS, version15.0; Inc., Chicago, IL, USA) was used for all statistical calculations. Continuous variables were given as mean \pm SD or median [interquartile range] as appropriate; categorical variables were defined as percentages. Data were tested for normal distribution using the KolmogorovSmirnov test. The Student's t-test was used for the univariate analysis of normally distributed continuous numerical variables, and Mann-Whitney U-test was used for non-normally distributed numerical variables. Categorical variables were compared with the Pearson chi-square or Fisher exact test. Correlations between variables were tested using the Pearson correlation test for normally distributed variables and the Spearman correlation test for non-normally distributed variables. Variables with a $p$-value $<0.05$ were included in the multivariate logistic regression analyses with the enter method. Receiver-operating characteristic (ROC) curve analysis was performed by using Med Calc software for variables that remained significant after multivariate analysis to. All tests of significance were two-tailed. All tests of significance were two-tailed. Statistical significance was defined as $p<0.05$.

\section{Results}

Office hypertension was detected in 48 of 102 subjects. The mean age of the patients was $52 \pm 8$ in the OHT group and $50 \pm 10$ in the healthy group $(p=0.06)$; male gender ratio was $42.1 \%(n=20)$ in the OHT group and $33.1 \%(n=18)$ in the healthy group $(p=0.4)$. There

Table 1: Baseline characteristics of the study population.

\begin{tabular}{|c|c|c|c|}
\hline Parameters $(\mathrm{N}=102)$ & OHT (N = 48) & NBP $(N=54)$ & $P$ value \\
\hline Sex (male), n (\%) & $20(42)$ & $18(33)$ & 0.4 \\
\hline Family history of CAD n (\%) & $7(15)$ & $15(28)$ & 0.08 \\
\hline Smoking, n (\%) & $11(23)$ & $21(39)$ & 0.07 \\
\hline Hyperlipidemia, n (\%) ${ }^{*}$ & $18(38)$ & $27(50)$ & 0.2 \\
\hline Age (years \pm SD) & $52 \pm 8$ & $50 \pm 10$ & 0.06 \\
\hline Hemoglobin (gr/dl) & $13.7 \pm 1.4$ & $12.7 \pm 1.5$ & 0.7 \\
\hline Glucose (mg/dl) & $103 \pm 93$ & $101 \pm 89$ & 0.5 \\
\hline Creatinine (mg/dL) & $0.9 \pm 0.3$ & $1.0 \pm 0.3$ & 0.144 \\
\hline Sodium & $139 \pm 4$ & $139 \pm 4$ & 0.811 \\
\hline Potassium & $4 \pm 0.4$ & $4 \pm 0.5$ & 0.758 \\
\hline cf-pulse wave velocity $\left(\mathrm{ms}^{-1}\right)$ & $9.0 \pm 1.7$ & $7.9 \pm 1.8$ & 0.002 \\
\hline Systolic Blood Pressure & $151 \pm 14$ & $118 \pm 10$ & 0.001 \\
\hline Diastolic Blood Pressure & $95 \pm 11$ & $74 \pm 9$ & 0.001 \\
\hline Body mass index & $31 \pm 5$ & $30 \pm 5$ & 0.5 \\
\hline Total Cholesterol (mg/dl) & $189 \pm 43$ & $191 \pm 46$ & 0.4 \\
\hline LDL (mg/dl) & $128 \pm 27$ & $131 \pm 30$ & 0.6 \\
\hline $\mathrm{HDL}(\mathrm{mg} / \mathrm{dl})$ & $41 \pm 3$ & $40 \pm 3$ & 0.8 \\
\hline Total Cholesterol (mg/dl) & $189 \pm 43$ & $191 \pm 46$ & 0.4 \\
\hline Triglyceride (mg/dl) & $175 \pm 36$ & $179 \pm 38$ & 0.6 \\
\hline
\end{tabular}

Chi-square test was performed for those with asterisk markings $\left(^{*}\right)$; OHT: Office Hypertension; NBP: Normal Blood Pressure 
was no difference between the groups in terms of other characteristics (Table 1).

However, cf-PWV measurements of the OHT group were significantly higher than the control group $(9.0 \pm$ $1.7 \mathrm{~m} / \mathrm{s}$ vs. $7.9 \pm 1.8 \mathrm{~m} / \mathrm{s}, \mathrm{p}=0.002$ ) (Figure 1). The cf-
PWV positively correlated with systolic blood pressure $(r$ $=0.310, p=0.002)$, age $(r=0.335, p=0.001)$, and bodymass index (BMI) ( $r=0.330, p=0.001$ ) (Table 2); and found to be an independent predictor of OHT (Table 3).

We constructed the ROC curve to evaluate whether

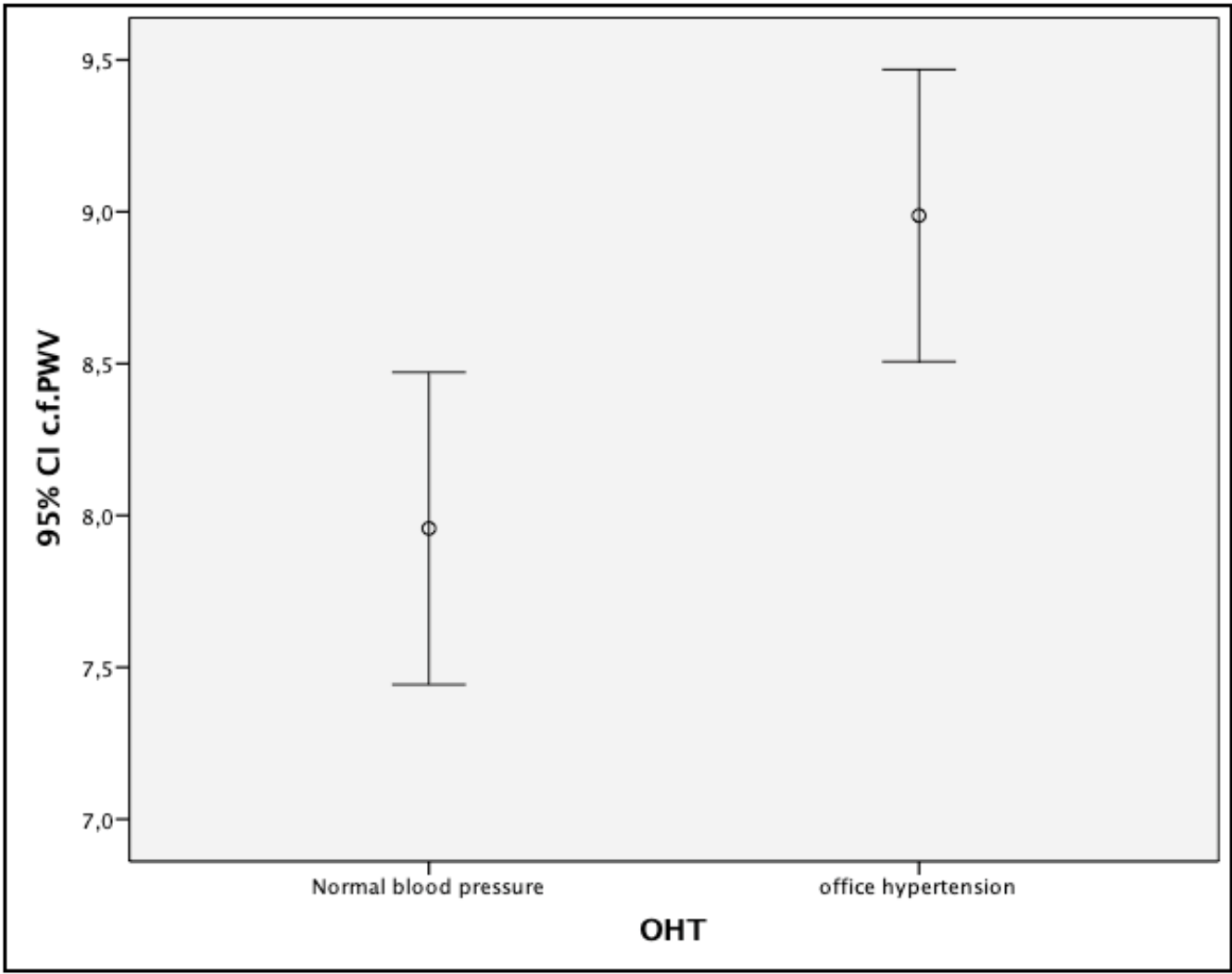

Figure 1: Association between aortic stiffness and wave reflection (cf-PWV) in patients with office hypertension (OHT) and normal blood pressure.

Table 2: Correlations of the surrogate markers with the parameters of Carotid-femoral pulse wave velocity (cf-PWV).

\begin{tabular}{|c|c|c|c|c|}
\hline Parameters & Systolic BP & Age & BMI & c-f PWV \\
\hline Systolic BP & - & $\begin{array}{l}r=0.199 \\
p=0.045\end{array}$ & $\begin{array}{l}r=0.123 \\
p=0.216\end{array}$ & $\begin{array}{l}r=0.310 \\
p=0.002\end{array}$ \\
\hline Age & $\begin{array}{l}r=0.199 \\
p=0.045\end{array}$ & - & $\begin{array}{l}r=0.009 \\
p=0.9\end{array}$ & $\begin{array}{l}r=0.335 \\
p=0.001\end{array}$ \\
\hline BMI & $\begin{array}{l}r=0.123 \\
p=0.216\end{array}$ & $\begin{array}{l}r=0.009 \\
p=0.9\end{array}$ & - & $\begin{array}{l}r=0.330 \\
p=0.01\end{array}$ \\
\hline cf-PWV & $\begin{array}{l}r=0.310 \\
p=0.002\end{array}$ & $\begin{array}{l}r=0.335 \\
p=0.001\end{array}$ & $\begin{array}{l}r=0.330 \\
p=0.01\end{array}$ & - \\
\hline
\end{tabular}

Systolic BP (blood pressure), age and BMI (body mass index) were correlated positively with cf-PWV.

Table 3: Results of multivariate analysis with logistic regression for $\mathrm{OHT}$.

\begin{tabular}{|l|l|l|l|}
\hline Independent Variables & †P value & B & Exp (B) Odds Ratio (95\% Confidence Interval) \\
\hline cf-PWV & 0.015 & 0.326 & $1.385(1.065-1.801)$ \\
\hline Age & 0.6 & 0.013 & $1.013(0.966-1.063)$ \\
\hline BMI & 0.7 & 0.014 & $0.986(0.908-1.070)$ \\
\hline Constant & 0.075 & & 0.046 \\
\hline R $^{2}$ Cox \& Snell/ Nagelkerke) & & & $0.82 / 0.110$ \\
\hline
\end{tabular}

†Variables with a $\mathrm{p}$ value $<0.05$ were included in the logistic regression analyses with enter method; OHT: Office Hypertension; BMI: Body Mass Index; cf-PWV: Carotid-Femoral Pulse Wave Velocity; OHT: cf-PWV increase increases Office hypertension 


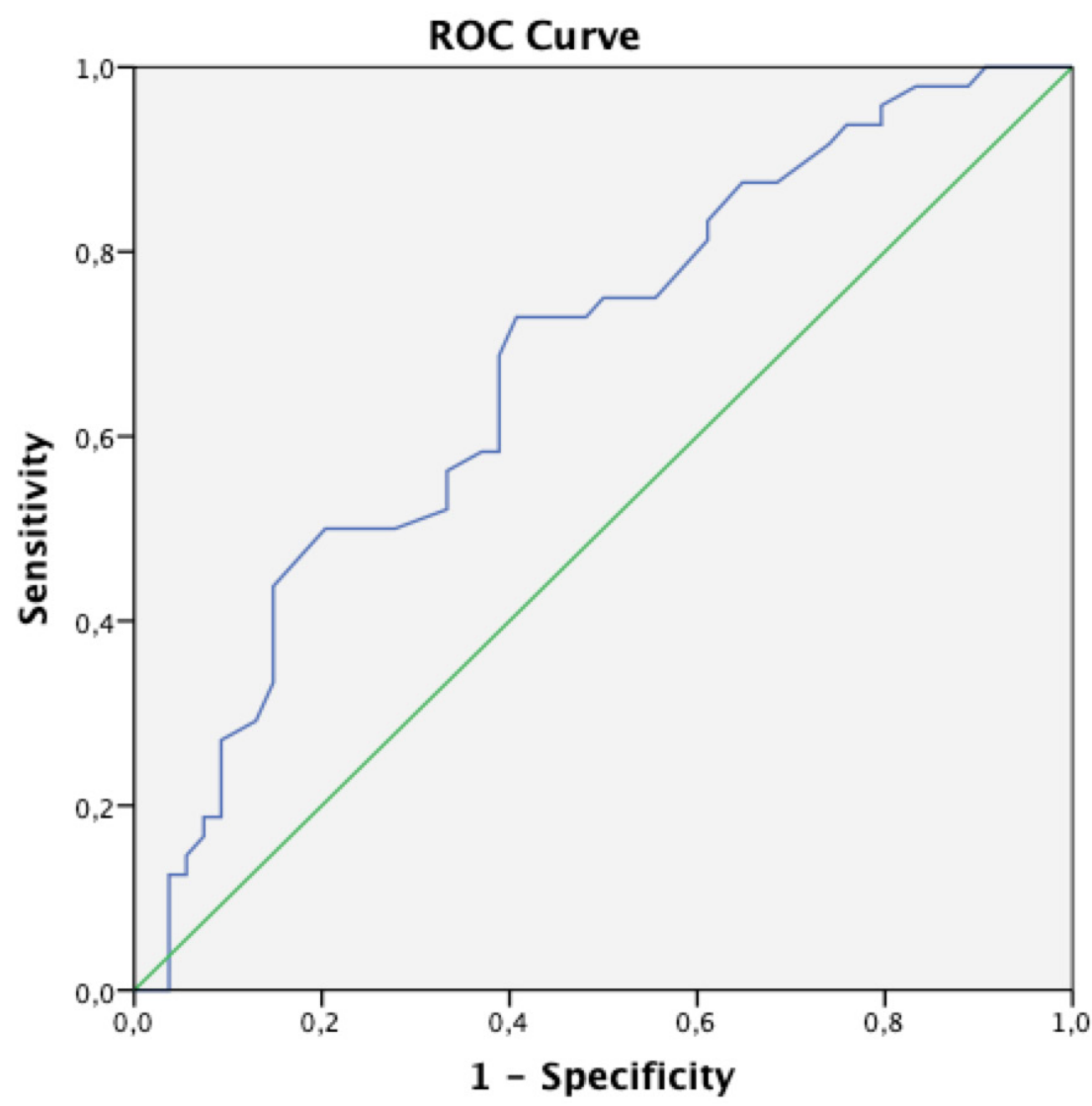

Figure 2: Receiver-operating characteristic curves (ROC) demonstrating the plot between sensitivity and specificity for cf$\mathrm{PWV}$ levels for the diagnosis of office hypertension (OHT).

or not cf-PWV levels could be used as a screening tool to exclude OHT. The cf-PWV levels were likely to exclude OHT with a sensitivity of $69 \%$ and a specificity of $61 \%$ (area under the curve $=0.681, p=0.002$ ) using a cut-off value of $8.25 \mathrm{cf}$-pulse wave velocity $(\mathrm{m} / \mathrm{s}$ ) (Figure 2 ).

\section{Discussion}

The current study evaluated the association between aortic stiffness and OHT, two markers of preclinical cardiovascular diseases. Study showed that subjects with isolated OHT had higher aortic stiffness and left ventricular hypertrophy prevalence than those with standard office/ambulatory blood pressure levels.

The systematic nature of the review provided the avoidance of bias in the choice of the study. Our findings confirm the well-established association of cf-PWV with age and blood pressure. Only a few studies have failed to show such relationships $[16,17]$. Their small sample size or narrow spread of age might cause it.

The significance of isolated OHT to predict future cardiovascular morbidity and mortality remains unsettled. Studies focusing on target-organ damage suggested that patients with isolated OHT might be at an intermediate risk between normotensive and those with sustained hypertension [18-20].

We may speculate that the increased left ventricular mass and aortic stiffness associated with uncontrolled isolated OHT may be due to neurohumoral, metabolic, or other factors irrelevant to blood pressure levels. An abnormal sympathetic response to environmental stimuli contributing to sudden rises in blood pressure can lead to cardiovascular damage [21]. However, the inadequacy of risk factors at the early stages of atherosclerosis on the stiffness of the arterial wall can explain the issue. Nevertheless, advanced plaque, particularly calcified, increases the stiffness of arteries [22]. This is supported by animal studies showing that PWV decreases in the early stages of a cholesterolrich diet and increases with the development of atherosclerotic plaques [23]. It is possible that, in advanced plaque, where plaque volume may relate to cardiovascular risk factors, the relation of PWV to risk factors may differ [24].

Cf-PWV diverges from classical risk factors other than blood pressure in terms of atherosclerosis and cardiovascular events. This suggests that, at least in initial stages, aortic stiffening is presented by an alternative pathology other than atherosclerosis in which blood pressure is one of the most significant factors.

Arterial stiffness depends on a mechanical stretch of the arterial wall and, hence, on blood pressure at the time of the measurement [25]. Stretch is thought to cause the stiffening of the wall by transferring the load to the members having a higher tensile strength (e.g., from elastin to collagen) in the wall. It is difficult to distinguish the effects of a sustained elevation 
of blood pressure (hypertension) from the level of blood pressure at the time of the study. Hypertension probably causes structural alterations within the wall by accelerating age-related changes such as a decrease in elastin-collagen ratio, a change in collagen type, and the formation of collagen cross-links from advanced glycation $[26,27]$.

The present review cannot figure out whether cfPWV is associated with hypertension or blood pressure at the time of the study. However, given the predictive power of cf-PWV for cardiovascular events over conventional measures of blood pressure (including ambulatory blood pressure monitoring), it is crucial to identify the factors responsible for increased stiffness. The cf-PWV probably relates more to the duration and severity of hypertension that cannot be captured by a spot measure of blood pressure at the time of the study. In this regard, cf-PWV can measure blood pressure "better" than the conventional office measurement.

High PWV values play a role in the pathophysiology of $\mathrm{OHT}$. Elevated blood pressure leads to increased aortic stiffness and PWV, causing target organ damage. Office hypertension may also lead to increased aortic stiffness, and thus PWV. Pulse wave velocity may, therefore, be an independent predictor of OHT. In the present study, we demonstrated that PWV could be used to predict and detect the OHT.

\section{Conclusion}

The patients with OHT have higher cf-PWV values compared with healthy subjects, and high PWV values play a role in the pathophysiology of OHT. Pulse wave velocity (PWV) is an independent predictor of OHT.

\section{Conflict of Interest}

None (There is no potential conflict of interest regarding the article or its submission).

\section{Animal and Human Rights Statements}

All procedures performed in studies involving human participants were in accordance with the ethical standards of the institutional and/or national research committee and with the 1964 Helsinki Declaration and its later amendments or comparable ethical standards.

\section{Funding Statement}

The funders had no role in study design, data collection, and analysis, decision to publish, or preparation of the manuscript.

\section{Scientific Responsibility Statement}

The authors declared that the article submitted was responsible for the scientific content of the article in the Copyright Transfer Form. These areas of responsibility include design, data collection, analysis and interpretation, content writing, preparation and scientific review, and the final version of the paper.

\section{References}

1. Verdecchia P, Reboldi GP, Angeli F, Schillaci G, Schwartz JE, et al. (2005) Short- and long-term incidence of stroke in white-coat hypertension. Hypertension 45: 203-208.

2. Demir A, Dincer MT (2019) The relation between body mass index and end organ damage in white coat hypertension. Marmara Medical Journal 32: 50-54.

3. Eguchi K, Hoshide S, Ishikawa J, Ishikawa S, Pickering TG, et al. (2008) Cardiovascular prognosis of sustained and white-coat hypertension in patients with type 2 diabetes mellitus. Blood Press Monit 13: 15-20.

4. Gustavsen $\mathrm{PH}, \mathrm{H} ø$ egholm A, Bang LE, Kristensen KS (2003) White coat hypertension is a cardiovascular risk factor: A 10-year follow-up study. J Hum Hypertens 17: 811-817.

5. Ohkubo T, Kikuya M, Metoki H, Asayama K, Obara T, et al. (2005) Prognosis of 'masked' hypertension and 'white-coat' hypertension detected by 24-h ambulatory blood pressure monitoring 10-year follow-up from the Ohasama study. J Am Coll Cardiol 46: 508-515.

6. Eapen DJ, Schultz WM, Heinl RE, Ghasemzadeh $\mathrm{N}$, Varghese T, et al. (2016) Primary prevention of cardiovascular disease. Cardiovascular Innovations and Applications 1: 379-389.

7. Sega R, Trocino G, Lanzarotti A, Carugo S, Cesana G, et al. (2001) Alterations of cardiac structure in patients with isolated office, ambulatory, or home hypertension: Data from the general population (Pressione Arteriose Monitorate E Loro Associazioni [PAMELA] study). Circulation 104: 1385-1392.

8. Palatini $\mathrm{P}$, Mormino $\mathrm{P}$, Santonastaso M, Mos L, Dal Follo M, et al. (1998) Target-organ damage in stage I hypertensive subjects with white-coat and sustained hypertension: Results from the HARVEST study. Hypertension 31: 57-63.

9. Dagli N, Dogdu O, Senarslan O, Yucel H, Kaya, H, et al. (2016) Relation of neutrophil/lymphocyte ratio to resistant hypertension. Eur Res J 2: 211-218.

10. Levy D, Garrison RJ, Savage DD, Kannel WB, Castelli WP (1990) Prognostic implications of echocardiographically determined left ventricular mass in the Framingham Heart Study. New Engl J Med 322: 1561-1566.

11. Laurent S, Boutouyrie P, Asmar R, Gautier I, Laloux B, et al. (2001) Aortic stiffness is an independent predictor of all-cause and cardiovascular mortality in hypertensive patients. Hypertension 37: 1236-1241.

12. Kramer CK, Leitao CB, Canani LH, Gross JL (2008) Impact of white-coat hypertension on microvascular complications in type 2 diabetes. Diabetes Care 31: 2233-2237.

13. Gökaslan S, Özer Gökaslan Ç, Demirel E, Çelik S (2019) Role of aortic stiffness and inflammation in the etiology of young-onset hypertension. Turk J Med Sci 49: 1748-1753.

14. De Angelis L, Millasseau SC, Smith A, Viberti G, Jones RH, et al. (2004) Sex differences in age-related stiffening of the aorta in subjects with type 2 diabetes. Hypertension 44: 67 71.

15. Mansia G, De Backer G, Dominiczak A, Cifkova R, Fagard R, et al. (2007) 2007 ESH-ESC Guidelines for the management of arterial hypertension: The taskforce for the management of arterial hypertension of the European Society of Hypertension (ESH) and of the European Society of Cardiology (ESC). Blood Press 16: 135-232. 
16. Avolio AP, Chen SG, Wang RP, Zhang CL, Li MF, et al (1983) Effects of aging on changing arterial compliance and left ventricular load in a northern Chinese urban community. Circulation 68: 50-58.

17. Avolio AP, Deng FQ, Li WQ, Luo YF, Huang ZD, et al. (1985) Effects of aging on arterial distensibility in populations with high and low prevalence of hypertension: Comparison between urban and rural communities in China. Circulation 71: $202-210$.

18. Sutton-Tyrrell K, Najjar SS, Boudreau RM, Venkitachalam L, Kupelian V, et al. (2005) Elevated aortic pulse wave velocity, a marker of arterial stiffness, predicts cardiovascular events in well-functioning older adults. Circulation 111: 3384-3390.

19. Willum-Hansen T, Staessen JA, Torp-Pedersen C, Rasmussen S, Thijs L, et al. (2006) Prognostic value of aortic pulse wave velocity as index of arterial stiffness in the general population. Circulation 113: 664-670.

20. Benetos A, Waeber B, Izzo J, Mitchell G, Resnick L, et al. (2002) Influence of age, risk factors, and cardiovascular and renal disease on arterial stiffness: Clinical applications. Am J Hypertens 15: 1101-1108.

21. Cardoso CRL, Ferreira MT, Leite NC, Barros PN, Conte $\mathrm{PH}$, et al. (2009) Microvascular degenerative complications are associated with increased aortic stiffness in type 2 diabetic patients. Atherosclerosis 205: 472-476.
22. Zureik M, Bureau JM, Temmar M, Adamopoulos C, Courbon D, et al. (2003) Echogenic carotid plaques are associated with aortic arterial stiffness in subjects with subclinical carotid atherosclerosis. Hypertension 41: 519-527.

23. Farrar DJ, Bond MG, Riley WA, Sawyer JK (1991) Anatomic correlates of aortic pulse wave velocity and carotid artery elasticity during atherosclerosis progression and regression in monkeys. Circulation 83: 1754-1763.

24. McLeod AL, Uren NG, Wilkinson IB, Webb DJ, Maxwell SR, et al. (2004) Non-invasive measures of pulse wave velocity correlate with coronary arterial plaque load in humans. J Hypertens 22: 363-368.

25. Berry CL, Greenwald SE (1976) Effects of hypertension on the static mechanical properties and chemical composition of the rat aorta. Cardiovasc Res 10: 437-451.

26. Kass DA, Shapiro EP, Kawaguchi M, Capriotti AR, Scuteri A, et al. (2001) Improved arterial compliance by a novel advanced glycation end-product crosslink breaker. Circulation 25: 1464-1470.

27. Faber M, Moller-Hou G (1952) The human aorta. V. Collagen and elastin in the normal and hypertensive aorta. Acta Pathol Microbiol Scand 31: 377-382. 